\title{
Analysis of Cusp Catastrophic Model for Vertical Stability of Drilling Shaft Lining
}

\author{
Jimin Liu $\mathbb{D}^{1,2}$ Hua Cheng $\mathbb{D}^{1,2,3}$ Chuanxin Rong, ${ }^{1,2}$ and Changbai Wang ${ }^{1,2}$ \\ ${ }^{1}$ School of Civil Engineering and Architecture, Anhui University of Science and Technology, Huainan 232001, China \\ ${ }^{2}$ State Key Laboratory of Mining Response and Disaster Prevention and Control in Deep Coal Mine, \\ Anhui University of Science and Technology, Huainan 232001, China \\ ${ }^{3}$ School of Resources and Environmental Engineering, Anhui University, Hefei 230601, China \\ Correspondence should be addressed to Hua Cheng; hcheng@aust.edu.cn
}

Received 15 September 2020; Revised 18 November 2020; Accepted 26 November 2020; Published 10 December 2020

Academic Editor: Yixian Wang

Copyright (C) 2020 Jimin Liu et al. This is an open access article distributed under the Creative Commons Attribution License, which permits unrestricted use, distribution, and reproduction in any medium, provided the original work is properly cited.

\begin{abstract}
The vertical stability analysis of the drilling shaft lining has long been a technical problem in the construction of underground space development projects. And the critical depth of vertical stability was a key parameter to judge its stability. To determine this parameter, a simple and practical computational method would be helpful. In this paper, a new vertical stability analysis model of shaft lining structure based on catastrophe theory was proposed. In accordance with the mechanical analysis, the catastrophic instability mechanics was analyzed and a new critical depth of drilling shaft lining was deduced. Further, the rationality and feasibility of the catastrophic calculation model was proved by the numerical simulation results in a case. And the sensitivity of the influencing parameters was also analyzed, which provided theoretic reference for optimization design and guiding security construction. The results implied that catastrophic calculation model, as an alternative method for shaft stability analysis, could be applied to theoretical analysis and guiding engineering practice in the study of drilling shaft lining's vertical stability.
\end{abstract}

\section{Introduction}

A drilling method of shaft sinking is a type of comprehensive drilling technology of full mechanization and is a special construction method for crossing deep, unstable aquifer formations in coal mine construction, which has been widely used in the shaft construction of coal mines, copper mines, and silver mines all over the world, as well as in subways, bridges, water conservancy, and hydropower and municipal engineering [1-8]. It involves drilling out the well holes using a large-scale drilling rig and mud wall protection simultaneously, and then, the prefabricated shaft segments are connected to the section one by one and suspended into the bottom of the shaft; finally, the shaft is cemented and filled using a cement slurry instead of mud to construct the coal drilling shaft mines. Figure 1 shows the schematic representation and the scene diagram of the shaft during suspension and subsidence. However, when the shaft lining is suspended and sinks to the bottom but has not yet been cemented and filled, the shaft lining will suddenly lean and slip if there is a slight eccentricity or lateral force, which would cause the shaft to be unstable. Moreover, the deeper the shaft is, the greater the possibility of the vertical instability of the shaft lining structure is. This may cause structural damage during construction and threats to security production. Therefore, ensuring its vertical stability is a practically technical problem in deep coal mine construction.

In view of the damage of instability to shaft lining structure, many scholars have studied this problem. They have regarded the critical depth as an important parameter to analyze and evaluate quantitatively. And the previous methods of determining the critical depth were all established using the energy method, and the instability criterion was determined by the principle of minimum potential energy. The corresponding theoretical analysis methods were relatively concentrated [9-17]. What is more, they have not given the practical guidance or specific measures on 


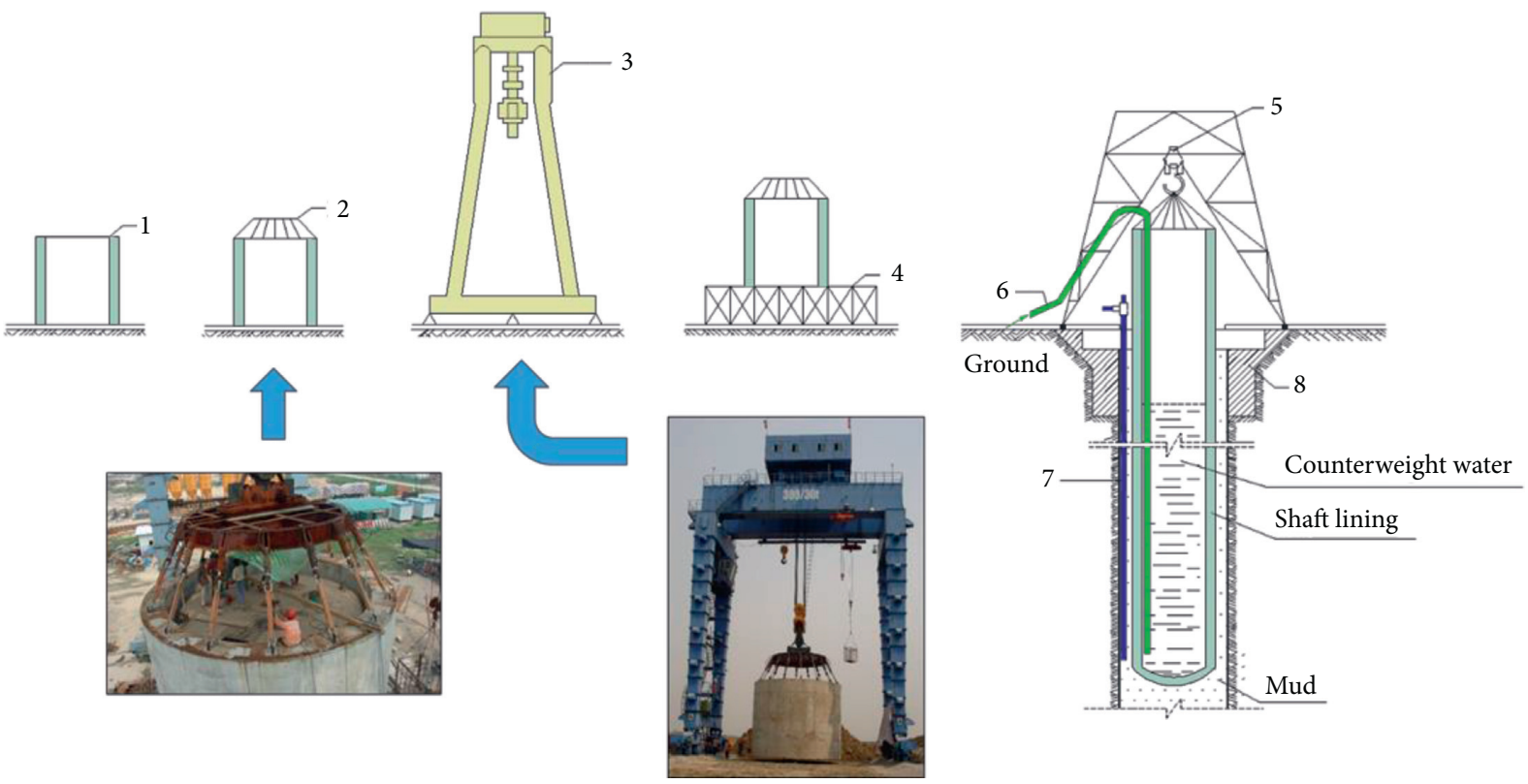

Figure 1: Schematic representation and the scene diagram of suspension and subsidence in drilling shaft sinking: (1) shaft segment; (2) hanging cap; (3) gantry crane; (4) drilling platform; (5) hook; (6) main water pipe; (7) pumping pipe; (8) guided wood.

adjusting structural stability. The research results were more inclined to theoretical analysis, which was not helpful to solve practical engineering problems.

In many engineering problems, the research object would be regarded as some constructional components, such as beams, plates, and shells, even some novel nanocomposite cases. These researches on components greatly facilitated our understanding of engineering problems and provided directions to solve practical problems. Civalek analyzed the free vibration of conical and cylindrical shells and annular plates made of composite laminated and functionally graded materials [18]. Arefi et al. studied size-dependent deflection analysis of FG graphene nanoplatelets (GNPs) reinforced composite microplates with porosity subjected to transverse load [19]. Ebrahimi et al. investigated static stability and free vibration characteristics of functionally graded (FG) nanobeams [20] and so on [21-24]. What is more, a suitable computational modeling and theoretical analysis could also help to solve practical engineering problems [25-29], especially in the underground engineering [30-33], which had experienced excellent performances. So, all the above results inspired us to establish a suitable mechanical model and mathematical modeling to get a new way to analyze the vertical instability of shaft lining structures.

During the construction of drilling shaft lining, the prefabricated shaft segments would be connected to the section one by one in the well hole and suspended into the bottom of the shaft. To protect the prefabricated segments and ensure the smooth operation of suspending, four wedges were fixed at the wellhead, whose contact condition could be considered as horizontal hinged joint. When the segments suspended and sunk to the bottom of the wellbore, the shaft segments would contact the bottom of the wellbore, whose contact condition could be considered as hinged joint too. Therefore, the shaft lining structure could be regarded as a slender compression rod hinged at both ends from the mechanical point of view. What is more, as the shaft segments were connected one by one, the construction deflection was inevitable and a slight eccentricity or lateral force would always occur, which aggravated the possibility of instability. Therefore, the mechanical characteristics of the drilling shaft lining conformed to the mechanical model of Euler slender compression column.

After further analysis, we found that the vertical instability of a drilling shaft in the process of suspension and subsidence is a complex abrupt and irreversible evolution process. With the shaft segments connected and lengthened in the mud one by one, the system's elastic potential energy gradually accumulates. When the elastic potential energy of the system accumulates to a certain extent, the shaft lining gradually develops from a slow and stable continuous change stage to a sudden state change instability damage stage, which is obviously characteristic of abrupt and irreversible evolution. Therefore, it is a good idea to introduce catastrophe theory (CT) into vertical stability analysis.

As an effective tool for studying discontinuity, singularity, and instability of systems, CT has been widely used in mining engineering, geotechnical engineering, and other underground mining activities [34-38]. Chen et al. categorized buckling instability of piles as a catastrophe failure and applied CT to the analysis of buckling stability. Considering the mechanical model of a top-free bottom-fixed pile and a top-hinged bottom-hinged pile, respectively, two cusp catastrophe models of the critical buckling load were proposed and the critical load for pile buckling damage was calculated. The calculated and test results were in good agreement [39]. Zhou et al. deduced the cusp catastrophe equation of pillar instability based on CT and obtained the criteria for pillar instability. This work contributed to mastering the failure laws of pillars and to laying theoretic 
foundation for feasible solutions to maintain the pillar and the goaf stability of gypsum mines [40]. Xia et al. established a catastrophic model to derive the equations calculating the critical water height in the splay fracture and the critical rainfall intensity and proposed the bedding-slip failure hydraulic criteria for bedding rock slope, which validated its rationality of instability mechanism by the physical model test [41]. Ma et al. derived the minimum thickness formula for an intervening pillar without instability under two different constraint conditions based on the cusp catastrophe theory [42].

As a new quantitative analysis method, CT and the cusp catastrophic model would be applied to analyze the vertical stability of drilling shaft linings. The idea of this article is shown in Figure 2. On the basis of constructing the geological mechanical model and the total potential energy function of the drilling shaft lining, a cusp catastrophic calculation model was established. Based on the equation of equilibrium surface and bifurcation set, the necessary and sufficient conditions for system instability were obtained, and the criterion for determining the catastrophic instability and the formula for calculating the vertical stabilization critical depth was derived. Meanwhile the factors that influence the critical depth were analyzed, respectively, and the sensitivity of the influencing parameters was also analyzed.

\section{Mechanical Analysis and Cusp Catastrophic Model}

For the analysis of the vertical stability of the drilling shaft lining during construction, the research object is generally chosen as the working condition when the shaft lining is suspended and subsides to the bottom of the shaft, but has not yet been cemented and filled. For the convenience of discussion, we assumed that the inner diameter of the shaft remained unchanged and the shaft lining structure and material used one specification. That is, the vertical stability of the drilling shaft lining with equal cross-sections and stiffness was studied. According to its construction characteristics, the shaft lining structure could be considered as a bottom tubular self-weight bar partially or totally filled with water in the mud fluid.

2.1. Mechanics Background. When the shaft is full of counterweight water, the force of the equal-section drilling shaft lining includes the self-weight of the shaft $P_{c}$, the lateral pressure of the mud on the outer surface of the shaft $P_{m}$, the lateral pressure of the counterweight water on the inner surface of the shaft $P_{w}$, the reverse force on the top of shaft $R_{B}$, and the reverse force on the bottom of the shaft $R_{A}$, which is shown in Figure 3(a). Because the displacement is not generated at the supports $A$ and $B$, the external force potential energy produced by $R_{A}$ and $R_{B}$ can be zero. The lateral pressure caused by the unit length mud on the outer surface of the shaft is

$$
f_{m}=\frac{\pi}{4} D^{2} \gamma_{m} \sin \alpha=q_{m} \sin \alpha
$$

The lateral pressure caused by the unit length counterweight water on the inner surface of the shaft is

$$
f_{w}=\frac{\pi}{4} d^{2} \gamma_{w} \sin \alpha=q_{w} \sin \alpha
$$

And its directions are along the normal direction of the deflection curve. The unit length self-weight of reinforced concrete shaft is

$$
q_{c}=\frac{\pi}{4}\left(D^{2}-d^{2}\right)\left[\gamma_{c}(1-\rho)+\gamma_{s} \rho\right]
$$

Among them, $D$ is the outer diameter of the shaft, $d$ is the inner diameter of the shaft, and $\gamma_{c}, \gamma_{s}, \gamma_{m}$, and $\gamma_{w}$ are the weights of concrete, steel, mud, and counterweight water, respectively.

2.2. Basic Assumption. Furthermore, we made the following basic assumptions:

(1) The material is elastic.

(2) The upper end of the shaft is the connecting rod support, the lower end is the articulated support, and its deflection curve equation is

$$
y=\delta \sin \frac{\pi x}{H}
$$

where $\delta$ is the maximum displacement at the midpoint of the deflection curve.

(3) Ignoring the effect of varying stiffness, shaft section's strength, stiffness, and inner diameter are the same.

(4) The structure of the shaft lining obeys the theory of small deflection of structural stability.

Based on the basic assumption 2 and the above force analysis, the equal-section drilling shaft lining's deformation curve and stability analysis diagram can be obtained in Figure 3(b), where $\alpha$ is the deflection curve inclination.

2.3. Total Potential Energy Function of Drilling Shaft Lining. The total potential energy of the drilling shaft structure is the sum of the strain energy $U$ and the external force potential energy $V$. Furthermore, the external force potential energy of the system could be understood as the sum of the external force potential energy caused by vertical force $V_{y}$ and the external force potential energy caused by the horizontal force $V_{x}$; therefore, the system's total potential energy function could be expressed as follows:

$$
\Pi=U+V=U+V_{x}+V_{y} .
$$

According to material mechanics, the external force potential energy caused by vertical force $P$ can be obtained by

$$
V_{y}=-P \lambda,
$$

where $\lambda$ is the tiny deformation of the system under the action of vertical force $P$, and the deformation $\lambda$ is 


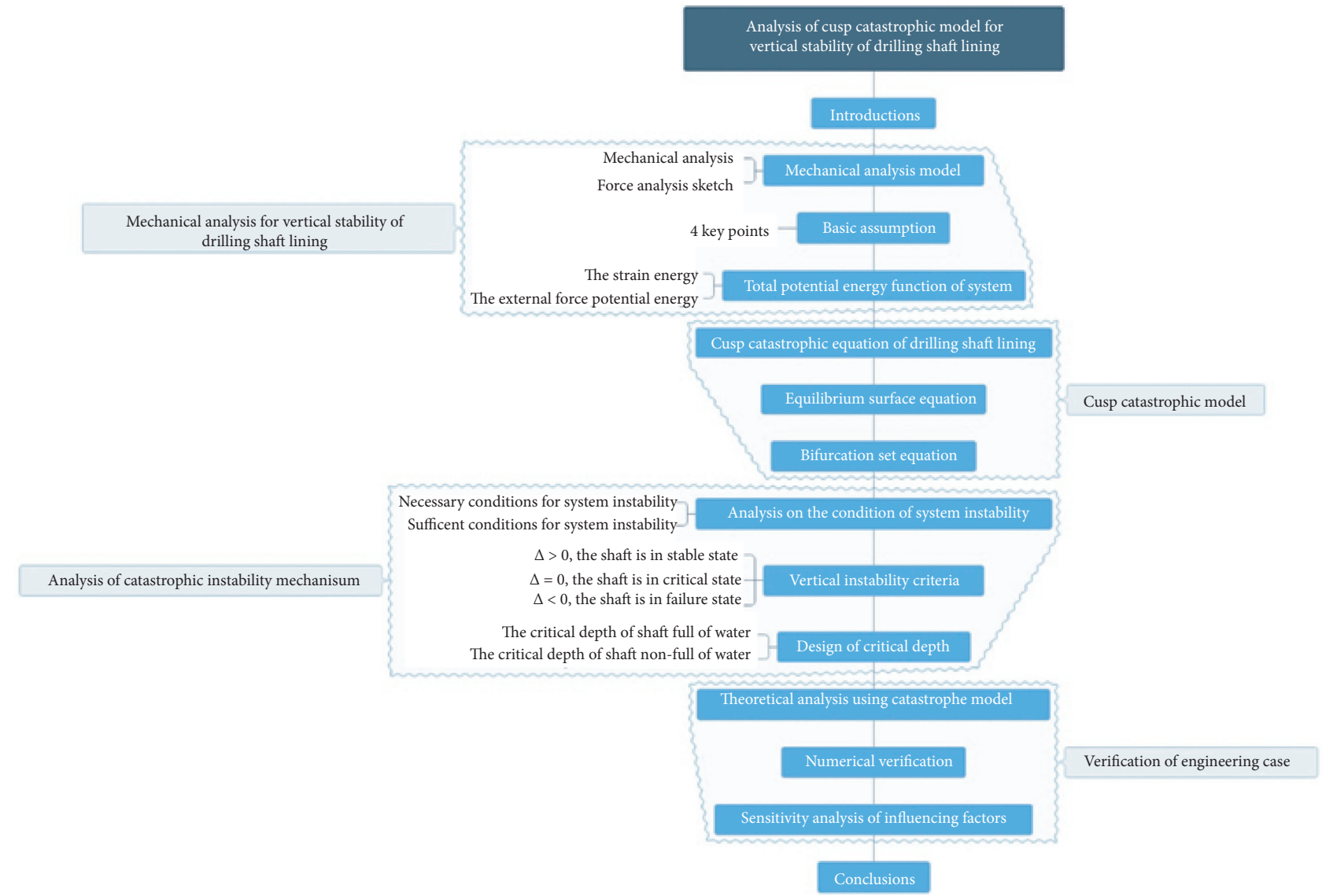

Figure 2: Content mind map of this article.

$$
\lambda=d_{s}-d_{x}=\left(\sqrt{1+\left(y^{\prime}\right)^{2}}-1\right) d_{x} B \frac{1}{2}\left(y^{\prime}\right)^{2} d_{x} .
$$

The external force potential energy caused by horizontal force $Q$ is the product of horizontal force $Q$ and displacement $y$; that is,

$$
V_{x}=Q y .
$$

Therefore, (5) can be expressed as follows:

$$
\Pi=U+V=U-P \lambda+Q y .
$$

According to assumption 4, there is no initial defect and stress in the bar, and only plane bending deformation occurs when the bar buckles, and the bending deformation is small; the expression is founded as

$$
M=-\mathrm{EI} \frac{y^{\prime \prime}}{\left(1+y^{\prime 2}\right)^{3 / 2}} B-\mathrm{EI} y^{\prime \prime}
$$

The deflection curve rotation angle $\alpha$ tends to zero, so

$$
\begin{aligned}
& \sin \alpha=y^{\prime}, \\
& \cos \alpha=1 .
\end{aligned}
$$

Therefore, the strain energy of the system could be expressed as

$$
U=\int_{0}^{H} \frac{M^{2}}{2 \mathrm{EI}} d_{x}=\frac{1}{2} \int_{0}^{H} \operatorname{EI}\left(y^{\prime \prime}\right)^{2} \mathrm{~d} x=\frac{\mathrm{EI} \pi^{4}}{4 H^{3}} \delta^{2} .
$$

As for the equal-section drilling shaft lining structure, the vertical force that may cause $V_{y}$ includes the self-weight of shaft lining $P_{c}$, the vertical component of mud lateral pressure $P_{m y}$, and the vertical component of the lateral pressure of counterweight water $P_{w y}$. Among them, the external force potential energy caused by the self-weight of the shaft can be determined from the formula

$$
V_{c}=-\frac{1}{2} \int_{0}^{H} q_{c}(H-x)\left(y^{\prime}\right)^{2} d_{x}=-\frac{\pi^{2} q_{c} \delta^{2}}{8} .
$$

The external force potential energy caused by the vertical component of the mud lateral pressure is

$$
\begin{aligned}
\left(V_{m}\right)_{y} & =\int_{0}^{H} f_{m} \sin \alpha x \lambda d_{x}=\int_{0}^{H} q_{m} \sin ^{2} \alpha x \frac{1}{2}\left(y^{\prime}\right)^{2} d_{x} \\
& =\frac{3 \pi^{4} q_{m}}{32 H^{2}} \delta^{4} .
\end{aligned}
$$

The external force potential energy caused by the vertical component of the counterweight water lateral pressure is 


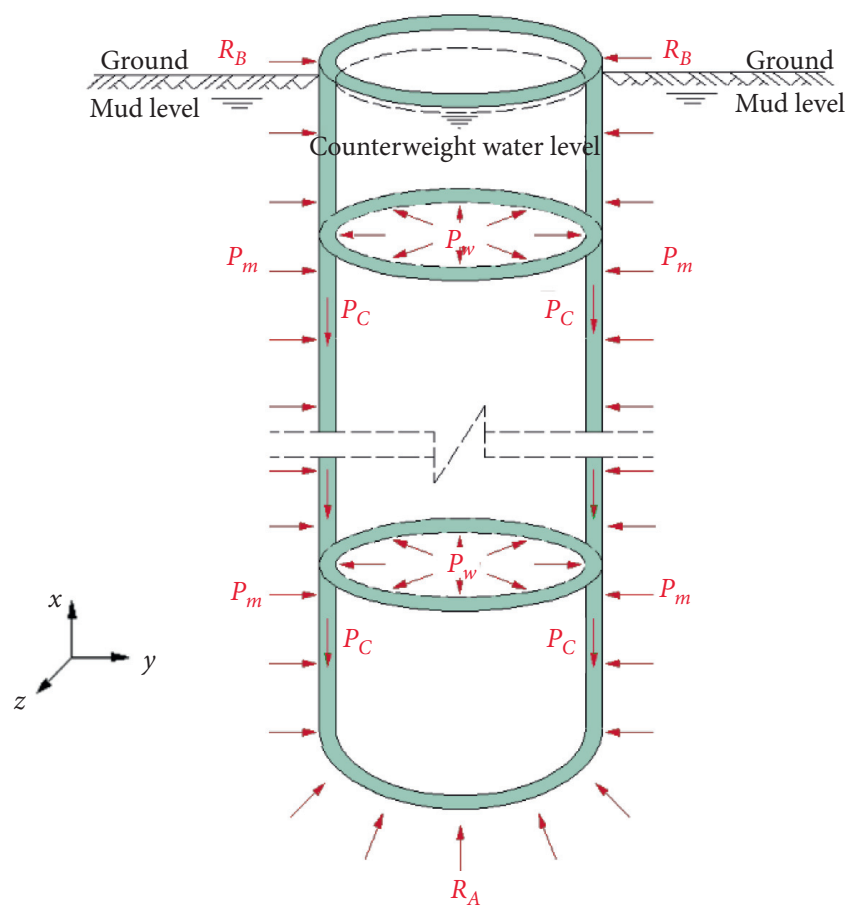

(a)

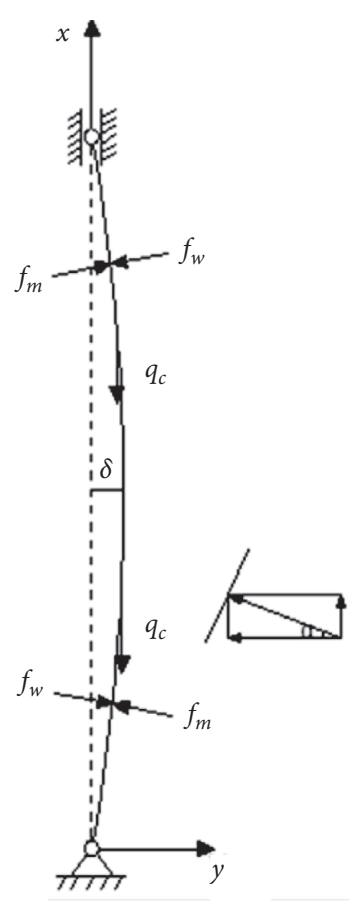

(b)

FIGURe 3: Mechanics model of equal-section drilling shaft lining full of water. (a) Force analysis sketch; (b) schematic diagram of stability analysis.

$$
\begin{aligned}
\left(V_{w}\right)_{y} & =-\int_{0}^{H} f_{w} \sin \alpha x \lambda d_{x}=-\int_{0}^{H} q_{w} \sin ^{2} \alpha x \frac{1}{2}\left(y^{\prime}\right)^{2} d_{x} \\
& =-\frac{3 \pi^{4} q_{w}}{32 H^{2}} \delta^{4} .
\end{aligned}
$$

The external force potential energy caused by the horizontal component of the lateral pressure of mud and counterweight water can be determined from the formulas

$$
\begin{aligned}
& \left(V_{m}\right)_{x}=\left(P_{m}\right)_{x} y=Q_{m} y=Q_{m} a \delta=Q_{m}^{\prime} \delta \\
& \left(V_{w}\right)_{x}=\left(P_{w}\right)_{x} y=Q_{w} y=Q_{w} a \delta=Q_{w}^{\prime} \delta . \\
& \text { If }\left(V_{m}\right)_{x}+\left(V_{w}\right)_{x}=Q^{\prime} \delta \\
& Q^{\prime}=Q_{m}^{\prime}+Q_{w}^{\prime}=a\left(\int_{0}^{H} f_{m} \cos \alpha d_{x}+\int_{0}^{H} f_{w} \cos \alpha d_{x}\right)
\end{aligned}
$$

where $a$ is a nonzero constant.

By substituting formulas (12)-(18) into formula (5), we obtain the total potential energy function of the system.

$$
\Pi=\frac{3 \pi^{4}}{32 H^{2}}\left(q_{m}-q_{w}\right) \delta^{4}+\left(\frac{E I \pi^{4}}{4 H^{3}}-\frac{\pi^{2} q_{c}}{8}\right) \delta^{2}+Q^{\prime} \delta
$$

2.4. Cusp Catastrophic Model of Drilling Shaft Lining with Equal Cross-Sections. Do equivalent transformation on (19), if

$$
\begin{aligned}
& A_{4}=\frac{3 \pi^{4}}{32 H^{2}}\left(q_{m}-q_{w}\right) . \\
& A_{2}=\frac{E I \pi^{4}}{4 H^{3}}-\frac{\pi^{2} q_{c}}{8} \\
& A_{1}=Q^{\prime} .
\end{aligned}
$$

Meanwhile, the dimensionless parameters $x, p$, and $q$ are introduced:

$$
\begin{aligned}
& x=\sqrt[4]{4 A_{4}} \cdot \delta, \\
& p=\frac{A_{2}}{\sqrt{A_{4}}}, \\
& q=\frac{A_{1}}{\left(4 A_{4}\right)^{1 / 4}} .
\end{aligned}
$$

The total potential energy function of the drilling shaft lining structure with equal cross-sections can be expressed as follows:

$$
\Pi(x)=\frac{1}{4} x^{4}+\frac{1}{2} p x^{2}+q x,
$$


where $x$ is a state variable and $p$ and $q$ are two control variables. According to Thom's classification theorem, the total potential energy function of the equal-section drilling shaft lining structure conforms to the cusp catastrophe mathematical model, which contains two control variables and one state variable. So the principle of the cusp catastrophe theory can be used to analyze the vertical stability of equal-section drilling shaft lining.

Let the first derivative of the total potential function be zero; the equilibrium surface equation of the system can be obtained as follows:

$$
\Pi^{\prime}(x)=x^{3}+p x+q=0
$$

The phase space of the equilibrium surface $M$ is threedimensional, and each point on it represents the equilibrium state of the system, and the surface is divided into upper, middle, and lower leaf. The equilibrium state of the shaft lining structure changes with the change of the state parameter $x$, and the different curved surface portions correspond to different stable equilibrium states. Among them, the lower and upper leaves are in stable equilibrium states, and the middle leaf is in an unstable equilibrium state.

Then deriving $x$ can obtain the critical state of the system:

$$
\Pi^{\prime \prime \prime}(x)=3 x^{2}+p=0 .
$$

The bifurcation set equation of the system can be obtained by combining (25) and (26):

$$
\Delta=4 p^{3}+27 q^{2}=0 .
$$

\section{Analysis of Catastrophic Instability Mechanism and Critical Depth Design}

In Figure 4, when the shaft structure is suspended and subsides, the elastic potential energy of the system keeps accumulating, and the state variable $x$ increases from low to high. $M(x, p, q)$, which represents the equilibrium state of the system, first develops from the lower leaf to the crease, that is, from the stable equilibrium state to the critical state of the stable equilibrium. Under the action of a small disturbance, the state parameter $x$ increases further, the system equilibrium point $M$ moves from the crease to the midleaf, and the shaft lining structure is in an unstable equilibrium state. But the middle leaf is always unreachable, and it will inevitably jump to the upper leaf at stable equilibrium, which results in catastrophic phenomena. Then the shaft structure will be destroyed by the catastrophic instability, and the system will transit from one stable equilibrium state to another stable equilibrium state. Therefore, it can be considered that the drilling shaft in the suspension and subsidence stage is located in the lower leaf of the balance surface, while the drilling shaft in the cemented and filled stage is located in the upper leaf of the balance surface, while the drilling shaft is suspended and subsided to the bottom but not yet cemented and filled stage is located in the middle leaf.

In the catastrophe theory, the values of the control variables $p$ and $q$ directly determine the stable state of the

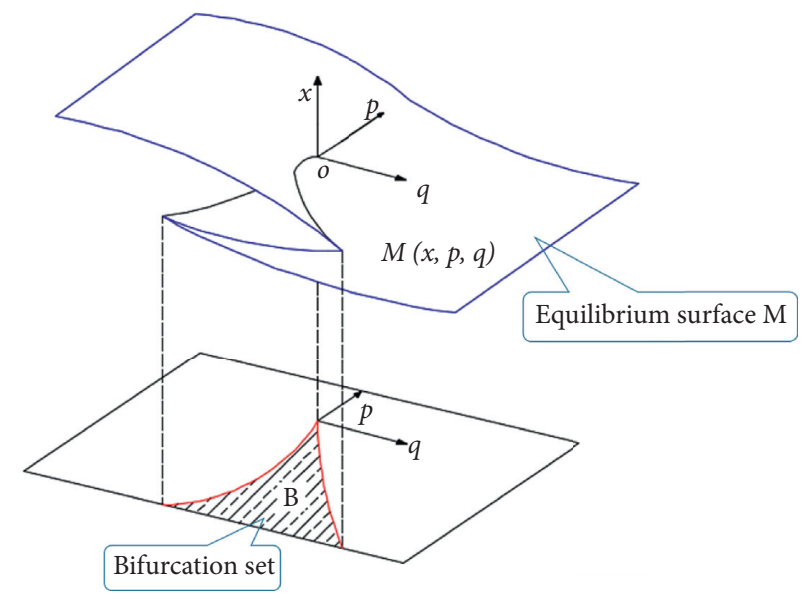

FIgURE 4: Equilibrium surface and the bifurcation set of cusp catastrophe model.

system. Therefore, the stable state of shaft structure can be defined by the selection of control variables $p$ and $q$, which provides a new method to determining the instability criteria and the critical depth of equal-section drilling shaft lining.

3.1. Necessary Conditions for System Instability. If and only if the equilibrium point of the system crosses the bifurcation set will the system have the possibility of vertical instability. Therefore, in the control plane of Figure 4, only when $p<0$, the equilibrium point of the system can cross the bifurcation set, which leads to the instability of the shaft structure. Therefore, the necessary conditions for the instability of the shaft structure with equal cross-sections are as follows:

$$
p=\frac{A_{2}}{\sqrt{A_{4}}}<0 .
$$

By substituting formulas (20) and (21) in formula (28), we obtain

$$
H>\sqrt[3]{\frac{2 \pi^{2} \mathrm{EI}}{q_{c}}} .
$$

3.2. Sufficient Conditions for System Instability. When the shaft structure is destroyed by a sudden change and instability, its state parameters must satisfy the bifurcation set equation (27). When (27) is set up, (25) has three real roots, two of which are equal. Two of the equilibrium states of the system are stable, and one is unstable. At this time, a stable state must jump from one branch to another, and then, the system will have a catastrophic instability. At this time, the system is the most sensitive to external disturbances and is in the critical state of instability. Therefore, the bifurcation set equation (27) is a sufficient condition for the shaft structural instability.

In formula (27), we found $27 q^{2} \geq 0$. If the formula (27) is set up, then

$$
4 p^{3}<0 .
$$


That is,

$$
p<0
$$

As a result, the sufficient and necessary conditions for the instability of the shaft lining structure are the same, and they all satisfy formulas (28) and (29).

3.3. Vertical Instability Criteria. According to CT, combined with the cusp catastrophe model and the bifurcation set equation, we know when

$$
\Delta=4 p^{3}+27 q^{2}>0
$$

The stable equilibrium point of the system lies outside the bifurcation set, the total potential energy of the system is minimized, and the system is in a stable equilibrium state. When formula (27) is set up, the stable equilibrium point of the system lies on the edge of the bifurcation set, and the system is in the critical state of a stable equilibrium.

$$
\Delta=4 p^{3}+27 q^{2}<0 .
$$

When the stable equilibrium point of the system is within the bifurcation set, the total potential energy of the system is the maximum, and the system is in an unstable equilibrium state. As

$$
\begin{aligned}
A_{1} & =Q^{\prime}=a\left(\int_{0}^{H} f_{m} \cos \alpha d_{x}+\int_{0}^{H} f_{w} \cos \alpha d_{x}\right) \\
& =\frac{a \pi\left(q_{m}+q_{w}\right) \delta}{H} \int_{0}^{H} \cos \frac{\pi x}{H} d_{x}=0
\end{aligned}
$$

in formula (27),

$$
\begin{aligned}
& q=0, \\
& A_{4}>0 \\
& \Delta=4 p^{3}=4 \frac{\left(\left(\mathrm{EI} \pi^{4} / 4 H^{3}\right)-\left(\pi^{2} q_{c} / 8\right)\right)^{3}}{\left(3 \pi^{4} / 32 H^{2}\left(q_{m}-q_{w}\right)\right)^{3 / 2}} .
\end{aligned}
$$

Therefore, the criteria for determining the vertical stability of an equal-section drilling shaft lining on the basis of the catastrophe theory can be summarized. If

$$
\begin{aligned}
& \Delta>0, \\
& H<H_{c r}=\sqrt[3]{\frac{2 \pi^{2} \mathrm{EI}}{q_{c}}},
\end{aligned}
$$

the shaft structure is in the stable state. If

$$
\begin{aligned}
& \Delta=0, \\
& H=H_{c r}=\sqrt[3]{\frac{2 \pi^{2} \mathrm{EI}}{q_{c}}},
\end{aligned}
$$

the shaft structure is in the critical state between stability and failure. If

$$
\begin{aligned}
& \Delta<0, \\
& H>H_{c r}=\sqrt[3]{\frac{2 \pi^{2} \mathrm{EI}}{q_{c}}},
\end{aligned}
$$

the shaft structure is in the failure state.

3.4. Design of Critical Depth. As mentioned above, when satisfying (37), the shaft is in the critical state. Thus, the formula for calculating the critical depth of the equal-section drilling shaft structure full of water is as follows:

$$
H_{c r}=\sqrt[3]{\frac{2 \pi^{2} \mathrm{EI}}{q_{c}}} .
$$

In drilling shaft construction, counterweight water is an important factor to control the vertical stability of the shaft lining structure. In practical engineering, sometimes it is not necessary to inject all the counterweight water, but to control the counterweight water within a reasonable range [43]. If the height of the counterweight water injected into the shaft is $H_{w}$, the external force potential energy caused by the lateral pressure of the counterweight water will change. At this time, the external force potential energy caused by the vertical counterweight water lateral pressure is as follows:

$$
\begin{aligned}
\left(V_{w}\right)_{y}= & -\int_{0}^{H_{w}} f_{w} \sin \alpha x \lambda d_{x}=-\int_{0}^{H_{w}} q_{w} \sin ^{2} \alpha x \frac{1}{2}\left(y^{\prime}\right)^{2} d_{x} \\
= & -\frac{3 \pi^{4} q_{w}}{32 H^{2}} \delta^{4}\left[\left(1-\frac{5}{2 \pi}\right)+4\left(\frac{H_{w}}{H} \sin \frac{2 \pi H_{w}}{H}\right.\right. \\
& \left.+\frac{1}{2 \pi} \cos \frac{2 \pi H_{w}}{H}\right)+\frac{1}{2}\left(\frac{H_{w}}{H} \sin \frac{4 \pi H_{w}}{H}\right. \\
& \left.\left.+\frac{1}{4 \pi} \cos \frac{4 \pi H_{w}}{H}\right)\right] \\
= & -\frac{3 \pi^{4} q_{w}}{32 H^{2}} \delta^{4} C .
\end{aligned}
$$

Here

$$
\begin{aligned}
C= & \left(1-\frac{5}{2 \pi}\right)+4\left(\frac{H_{w}}{H} \sin \frac{2 \pi H_{w}}{H}+\frac{1}{2 \pi} \cos \frac{2 \pi H_{w}}{H}\right) \\
& +\frac{1}{2}\left(\frac{H_{w}}{H} \sin \frac{4 \pi H_{w}}{H}+\frac{1}{4 \pi} \cos \frac{4 \pi H_{w}}{H}\right) .
\end{aligned}
$$

Further, the external force potential energy caused by the horizontal counterweight water lateral pressure is as follows:

$$
\begin{aligned}
\left(V_{w}\right)_{x} & =-\int_{0}^{H_{w}} f_{w} \cos \alpha y d_{x}=-\int_{0}^{H_{w}} q_{w} \sin \alpha y d_{x} \\
& =-\frac{q_{w}}{2} \sin ^{2} \frac{\pi H_{w}}{H} \delta^{2} .
\end{aligned}
$$

So the total potential energy function when the equalsection drilling shaft lining is non-full-water is as follows: 


$$
\begin{aligned}
\Pi= & \frac{3 \pi^{4}}{32 H^{2}}\left(q_{m}-q_{w} C\right) \delta^{4}+\left(\frac{\mathrm{EI} \pi^{4}}{4 H^{3}}-\frac{\pi^{2} q_{c}}{8}-\frac{q_{w}}{2} \sin ^{2} \frac{\pi H_{w}}{H}\right) \delta^{2} \\
& +Q^{\prime} \delta .
\end{aligned}
$$

Here,

$$
p=\frac{\left(\mathrm{EI} \pi^{4} / 4 H^{3}\right)-\left(\pi^{2} q_{c} / 8\right)-\left(q_{w} / 2\right) \sin ^{2}\left(\pi H_{w} / H\right)}{\sqrt{3 \pi^{4} / 32 H^{2}\left(q_{m}-q_{w} C\right)}} .
$$

According to the necessary and sufficient conditions and the judgment criteria of the catastrophe theory, the formula for calculating the critical depth of the vertical stability of the drilling shaft under the condition of non-full-water with equal cross-sections is obtained as follows:

$$
H_{c r}=\sqrt[3]{\frac{2 \mathrm{EI} \cdot \pi^{4}}{q_{c} \cdot \pi^{2}+4 q_{w} \sin ^{2}\left(\pi H_{w} / H\right)}} .
$$

If $H_{w}=H$ is chosen in formula (45), the conclusion is the same as that of formula (39).

So up to now, we get the vertical instability criteria and the critical depth of drilling shaft lining structure. The flow chart of vertical stability analysis of drilling shaft lining by catastrophe model is shown in Figure 5. We can analyze and judge the vertical stability of shaft lining and put forward constructive suggestions to guide practical engineering according to this flow chart.

\section{Verification of Engineering Case}

4.1. General Geological Background. A ventilation shaft of a mine in this case was located in Huainan city, Anhui province. Its actual engineering parameters were as follows in Table 1. This was a reinforced concrete composite shaft lining. And it was composed of 15 sections with different heights, thicknesses, and materials. It is mainly composed of reinforced concrete with different strength grades, high strength or high performance concrete, and steel-concrete composite with different thickness.

\subsection{Theoretical Analysis of Catastrophe Calculation Model.} To evaluate the shaft's vertical stability during construction, we chose 6 calculated heights and calculated its critical depth by using formula (45), respectively. Based on the vertical stability criteria established in this study, if the critical depth was less than the calculated height, the shaft lining was unstable, and if the critical depth was more than the calculated height, the shaft lining was stable. As the basic assumption 3, the parameters such as the elastic modulus of the shaft structure, moment of inertia of the cross-section, self-weight per unit length of the shaft, and the inner diameter should be taken as weighted values after height modification.

Therefore, the critical depth at different calculated heights was calculated and the result of structural stability

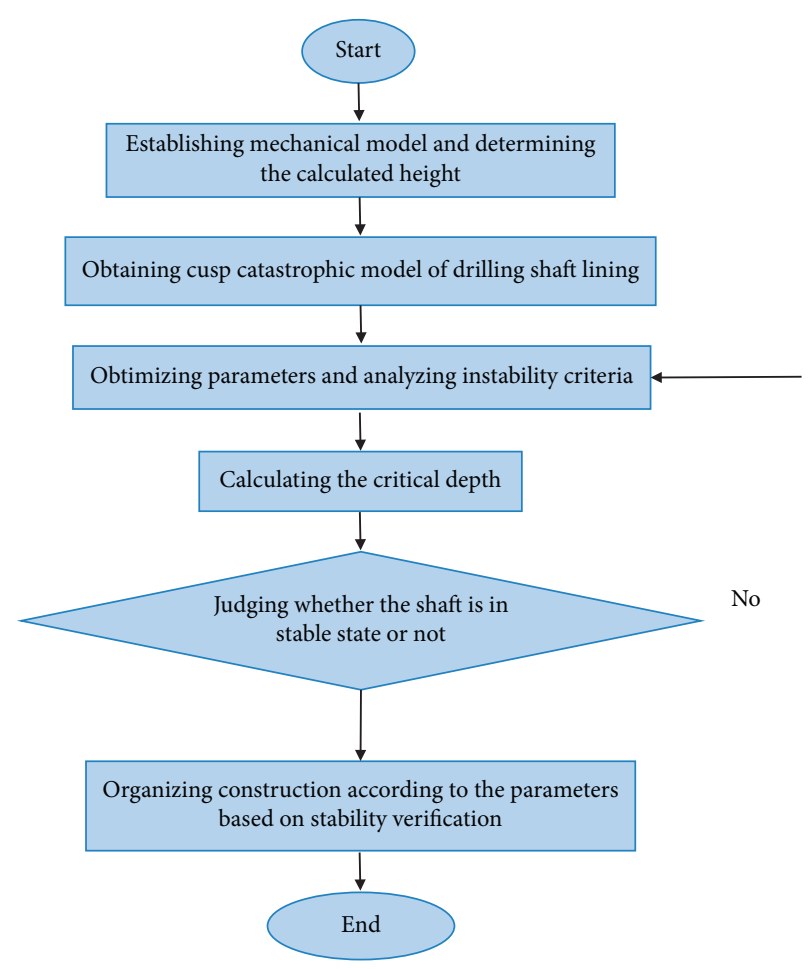

Figure 5: Flow chart of vertical stability analysis of drilling shaft lining by catastrophe model.

obtained, which is shown in Table 2. These results indicated that some necessary measures should be taken when its construction height attached $H_{5}$, which was the most important information obtained from the catastrophe calculation model. As this project was already under construction, we could only take measures according to the progress of the project. So we adjusted the inner diameter of shaft segments and the injection volume of counterweight water when its construction height reached $600 \mathrm{~m}$ and emphasized real-time monitoring. In the last $60 \mathrm{~m}$ shaft lining construction, the construction process was smooth and steady and there were no circumstances of instability. All the calculation conclusions and relevant measures verified and ensured the safe construction of this projection.

4.3. Validation of Numerical Simulation. The problem of shaft's stability was attributed to Euler stability. This stability was determined by the incremental solution of extreme stability and the generalized eigenvalue solution of Euler stability in numerical analysis [44-46]. The numerical simulation could be carried out by using the finite element software ABAQUS, and the structural stability of the shaft could be analyzed. When $\lambda<0$, the shaft was stable; when $0<\lambda<1$, the shaft was unstable; and when $\lambda>1$, the shaft was stable. The eigenvalues of the shaft lining at different calculated heights could be calculated, and the stability of the shaft lining was analyzed and determined according to the above analysis. The finite element calculation results are listed in Table 2. 
TABLE 1: Calculating parameter table of the drilling shaft lining.

\begin{tabular}{|c|c|c|c|c|c|c|c|c|c|c|}
\hline $\begin{array}{l}\text { Shaft } \\
\text { type }\end{array}$ & Shaft material & $\begin{array}{l}\text { Segment } \\
\text { height }(\mathrm{m})\end{array}$ & $\begin{array}{c}\text { Shaft } \\
\text { thickness } \\
(\mathrm{mm})\end{array}$ & $\begin{array}{c}\text { Inner } \\
\text { diameter } \\
(\mathrm{m})\end{array}$ & $\begin{array}{l}\text { Strength } \\
\text { grade of } \\
\text { concrete }\end{array}$ & \multicolumn{2}{|c|}{$\begin{array}{l}\text { Steel plate } \\
\text { thickness }\end{array}$} & $\begin{array}{c}\text { Elastic } \\
\text { modulus } \\
(\mathrm{GPa})\end{array}$ & $\begin{array}{c}\text { Cross- } \\
\text { sectional } \\
\text { moment of } \\
\text { inertia }\left(\mathrm{m}^{4}\right)\end{array}$ & $\begin{array}{l}\text { Self-weight } \\
\text { per unit } \\
\text { length of shaft } \\
\left(10^{5} \mathrm{~N} / \mathrm{m}\right)\end{array}$ \\
\hline S1 & $\begin{array}{l}\text { Reinforced } \\
\text { concrete }\end{array}$ & 22.4 & 550 & 7.2 & C30 & & & 31.26 & 100.86 & 3.33 \\
\hline S2 & $\begin{array}{l}\text { Reinforced } \\
\text { concrete }\end{array}$ & 72 & 550 & 7.2 & C30 & & & 31.26 & 100.86 & 3.33 \\
\hline S3 & $\begin{array}{l}\text { Reinforced } \\
\text { concrete }\end{array}$ & 30 & 550 & 7.2 & $\mathrm{C} 40$ & & & 33.74 & 100.86 & 3.33 \\
\hline S4 & $\begin{array}{l}\text { Reinforced } \\
\text { concrete }\end{array}$ & 30 & 550 & 7.2 & C50 & & & 35.73 & 100.86 & 3.33 \\
\hline S5 & $\begin{array}{l}\text { Reinforced } \\
\text { concrete }\end{array}$ & 90 & 750 & 6.8 & C50 & & & 35.73 & 127.78 & 4.42 \\
\hline S6 & $\begin{array}{l}\text { Reinforced } \\
\text { concrete }\end{array}$ & 54 & 750 & 6.8 & C60 & 18 & 18 & 37.22 & 127.78 & 4.42 \\
\hline S7 & $\begin{array}{l}\text { Reinforced } \\
\text { concrete }\end{array}$ & 85 & 900 & 6.5 & C60 & 18 & 18 & 37.22 & 145.08 & 5.2 \\
\hline S8 & $\begin{array}{c}\text { Steel-concrete } \\
\text { composite }\end{array}$ & 60 & 900 & 6.5 & C60 & 10 & 10 & 40.84 & 145.08 & 5.37 \\
\hline S9 & $\begin{array}{l}\text { Steel-concrete } \\
\text { composite }\end{array}$ & 48 & 900 & 6.5 & C70 & 16 & 10 & 41.86 & 145.08 & 5.43 \\
\hline S10 & $\begin{array}{l}\text { Steel-concrete } \\
\text { composite }\end{array}$ & 32 & 900 & 6.5 & C70 & 20 & 16 & 43.83 & 145.08 & 5.56 \\
\hline S11 & $\begin{array}{l}\text { Steel-concrete } \\
\text { composite }\end{array}$ & 32 & 900 & 6.5 & C70 & 25 & 20 & 45.53 & 145.08 & 5.66 \\
\hline S12 & $\begin{array}{l}\text { Steel-concrete } \\
\text { composite }\end{array}$ & 76 & 900 & 6.5 & C70 & 30 & 25 & 47.46 & 145.08 & 5.79 \\
\hline S13 & $\begin{array}{l}\text { Steel-concrete } \\
\text { composite }\end{array}$ & 24 & 650 & 7.0 & C70 & 20 & 16 & 46.5 & 114.9 & 4.27 \\
\hline S14 & $\begin{array}{l}\text { Reinforced } \\
\text { concrete }\end{array}$ & 1.6 & 650 & 7.0 & $\mathrm{C} 70$ & & & 38.21 & 114.9 & 3.88 \\
\hline S15 & $\begin{array}{l}\text { Reinforced } \\
\text { concrete }\end{array}$ & 3 & 650 & 7.0 & C70 & & & 38.21 & 114.9 & 3.88 \\
\hline
\end{tabular}

TABle 2: Analysis comparison table between catastrophe model and finite element calculation.

\begin{tabular}{|c|c|c|c|c|c|c|c|c|c|c|c|}
\hline \multicolumn{9}{|c|}{ Catastrophic calculation model } & \multicolumn{3}{|c|}{ Finite element calculation } \\
\hline $\mathrm{H}(\mathrm{m})$ & $\mathrm{Hw}(\mathrm{m})$ & $\mathrm{E}(\mathrm{GPa})$ & $\mathrm{I}\left(\mathrm{m}^{4}\right)$ & $\begin{array}{c}\mathrm{qc} \\
\left(10^{5} \mathrm{~N} / \mathrm{m}\right)\end{array}$ & $\begin{array}{c}\mathrm{qw} \\
\left(10^{5} \mathrm{~N} / \mathrm{m}\right)\end{array}$ & $\operatorname{Hcr}(\mathrm{m})$ & Judgment criteria & Conclusion & First-order eigenvalue & Second-order eigenvalue & Conclusion \\
\hline 28.275 & 13.4 & 45.247 & 114.9 & 4.211 & 3.770 & 593.48 & $H<H_{c r}$ & Stable & -937.190 & -937.190 & Stable \\
\hline 216.275 & 55.203 & 45.105 & 141.134 & 5.45 & 3.316 & 588.95 & $H<H_{c r}$ & Stable & 24.493 & 24.493 & Stable \\
\hline 361.275 & 89.800 & 42.54 & 142.718 & 5.378 & 3.23 & 583.10 & $H<H_{c r}$ & Stable & 5.40050 & 5.40050 & Stable \\
\hline 505.275 & 171.064 & 40.76 & 138.46 & 5.105 & 3.364 & 568.69 & $H<H_{c r}$ & Stable & 1.98960 & 1.98960 & Stable \\
\hline 565.275 & 216.739 & 40.12 & 134.47 & 4.947 & 3.428 & 566.83 & $H<H_{c r}$ & Stable & 1.44130 & 1.41130 & Stable \\
\hline 659.675 & 291.703 & 38.85 & 139.66 & 4.69 & 3.51 & 557.12 & $H>H_{c r}$ & Unstable & 0.90531 & 0.90531 & Unstable \\
\hline
\end{tabular}

As shown in the table, when the calculation height was 28.275 m, 216.275 m, 361.275 m, 505.275 m, and $565.275 \mathrm{~m}$, the first-order eigenvalue and second-order eigenvalue were all greater than 1 , and the shaft was stable. When the calculation height was $659.675 \mathrm{~m}$, the first-order eigenvalue and second-order eigenvalue were all less than 1 , and the shaft was unstable. What is more, the higher the calculation height was, the smaller the eigenvalue was, and the structure was more inclined to be unstable. Further, by comparing the finite element calculation results and the catastrophic model calculation results in Table 2, it was found that the theoretical analysis results based on catastrophe theory also showed the same stability judgment result. That is to say, the judgment conclusions obtained by the numerical simulation were in complete agreement with the stability judgment conclusions obtained by using the cusp catastrophic calculation model. This considerably verified the reliability of the catastrophe model in the study of the vertical stability of a drilling shaft.

4.4. Influencing Factors and Sensitivity Analysis. By combining formula (39) with formula (45), we designed orthogonal experiments according to the properties of the shaft lining materials, the diameter of the shaft lining, and the height of the counterweight water. The single-factor progressive law of the influencing factors of the critical depth of reinforced concrete and steel plate concrete composite shaft lining could be further studied. The influence law curve is shown in Figures $6-8$, in which S1 represented a 


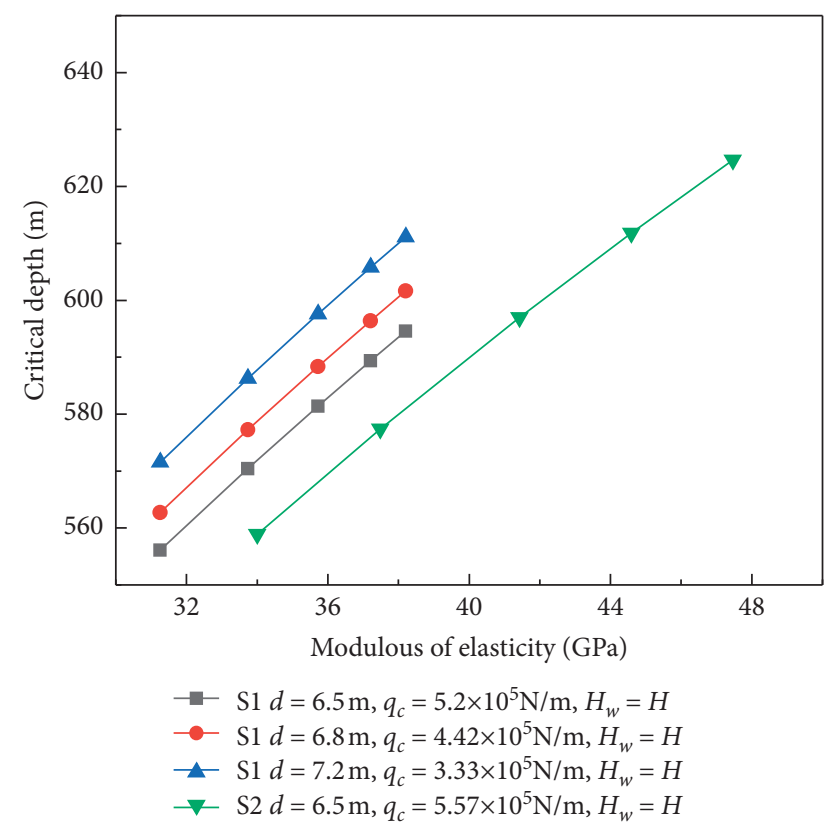

FIGURE 6: Relationship between elastic modulus and critical depth.

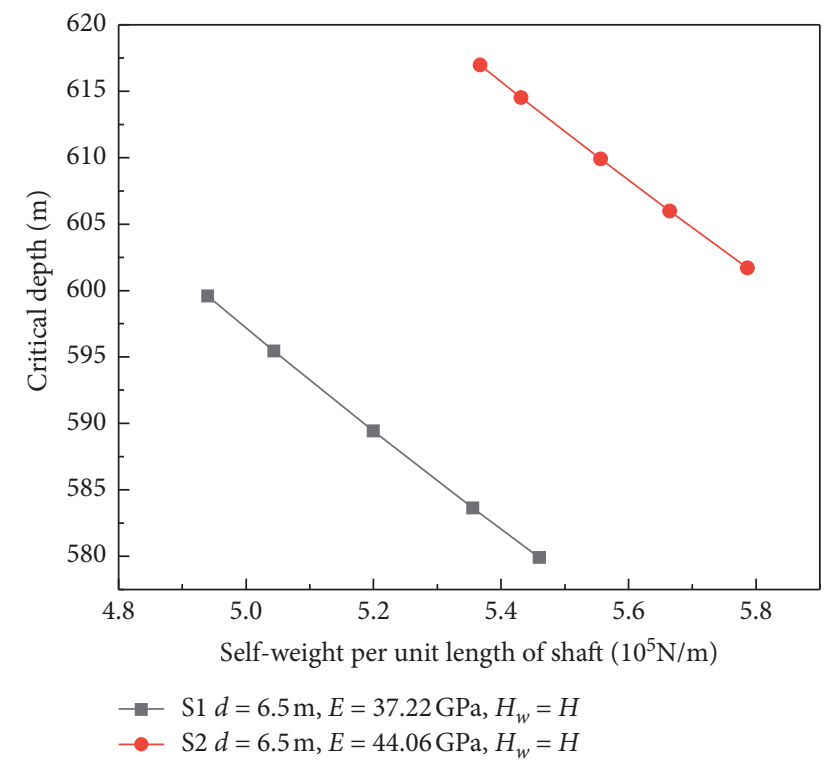

FIGURE 7: Relationship between self-weight per unit length of shaft and critical depth.

reinforced concrete shaft lining and S2 represented a steel plate concrete composite shaft lining. For the convenience of discussing this problem, the shaft in Figures 6 and 7 was full of counterweight water, that is to say, $H_{w}=H=659.675 \mathrm{~m}$.

It can be seen from Figures 6-8 that, under the same other conditions, with an increase in the concrete strength grade, both the composite elastic modulus and the critical depth of the vertical stability of the shaft lining increased gradually. The larger the inner diameter of the shaft lining was, the lower the critical depth was. The larger the weight of the shaft lining per unit length was, the smaller the critical

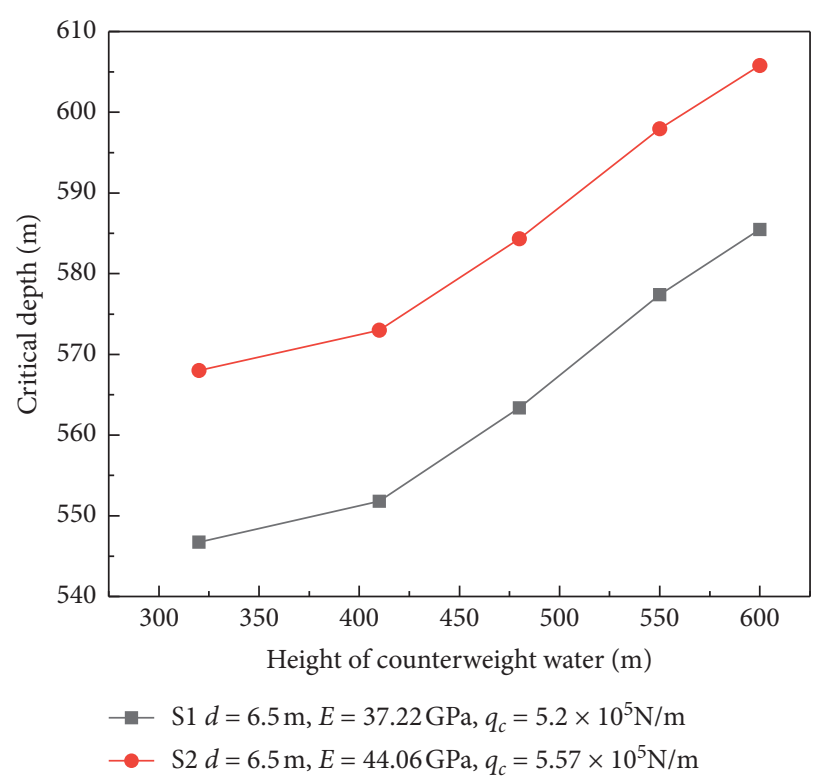

FIGURE 8: Relationship between height of counterweight water and critical depth.

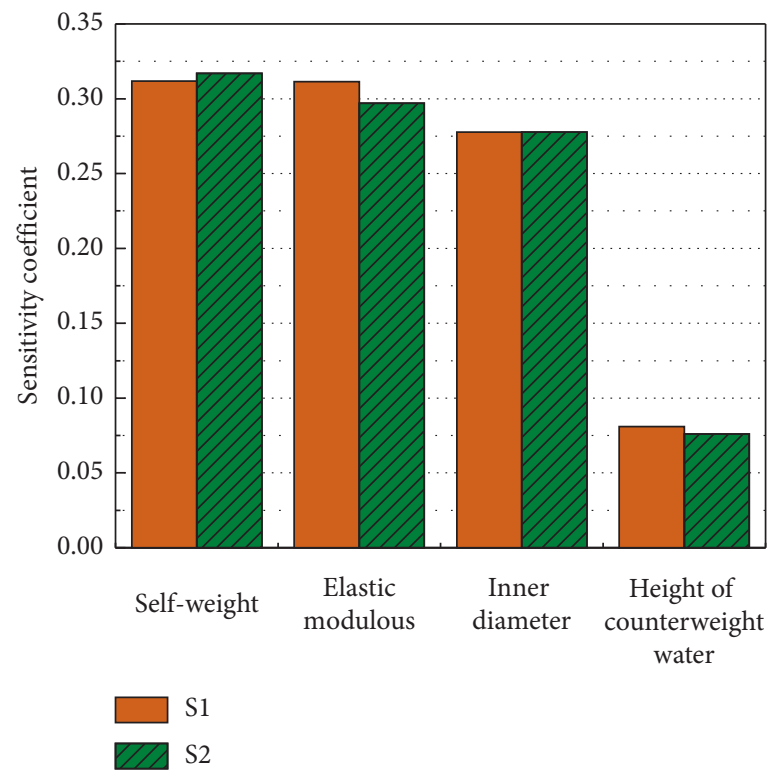

FIgURE 9: Sensitivity analysis chart of influencing factors.

depth was. The higher the height of the counterweight water was, the higher the critical depth was.

The sensitivity of each influencing factor was also important to the result and was calculated, respectively [47-50]. For the reinforced concrete shaft lining, the sensitivity coefficients of the self-weight per unit length, elastic modulus, inner diameter, and height of the counterweight water were: $0.3117,0.3113,0.2777,0.1018$. For the steel plate concrete composite shaft lining, the sensitivity coefficients of the self-weight per unit length, elastic modulus, inner diameter, and height of counterweight water were 0.3169 , $0.297,0.2777$, and 0.076 , respectively. Therefore, the 
sensitivity coefficients for two kinds of shaft lining structure were ranked from high to low: self-weight $>$ elastic modulus $>$ inner diameter $>$ height of water, which is shown in Figure 9.

This order compared and quantified each influencing parameter and suggested to us which measure was more effective when we optimized the shaft structure before construction and took measures under construction. For example, we would choose light weight shaft materials instead of controlling the injection volume of counterweight water because the measures of adjusting the self-weight of shaft lining structure were more effective than the measures of controlling the height of counterweight water.

\section{Conclusions}

On the basis of the cusp catastrophic calculation model, the stability of a shaft lining was analyzed in this study, and the following conclusions were obtained:

(1) In view of the fact that the shaft lining transferred from a stable equilibrium state to another stable equilibrium state during its suspension and subsidence, it had the characteristics of abrupt and irreversible evolution, the catastrophe theory was proposed to analyze this problem, which provided a new quantitative analysis for the theoretical analysis of vertical stability of drilling shaft lining.

(2) From the point of mechanics, the process during suspending and sinking of shaft lining can be regarded as a Euler compressed slender rod. Its cusp catastrophic model was established after analysis and calculation rigorously. The necessary and sufficient conditions for the vertical instability of the drilling shaft were analyzed, the criterion for determining the stability of the shaft structure was obtained, and a new formula for calculating the vertical stabilization critical depth with full-water and non-full-water was derived.

(3) Combining these with engineering examples, we calculated the critical depth of the shaft lining and analyzed the stability of the shaft lining structure. Its judgment conclusion was the same as that of the numerical calculation and analysis, which proved the rationality and feasibility of the catastrophic calculation model.

(4) The change rule of the influencing factors of the critical depth and the sensitivity of these influencing factors were also analyzed. The order of sensitivity of these influencing factors was as follows: selfweight $>$ elastic modulus $>$ inner diameter$>$ counterweight water height. These conclusions were of significance in that they provide theoretic reference for the optimization design, as well as for guiding safety construction.

(5) The analysis method based on catastrophic calculation model not only enriched the theoretical research method of shaft lining structure stability, but also provided practical control measures for shaft lining construction. Their perfect performance in the guidance of theory and practice has greatly enriched the research results.

\section{Data Availability}

All data generated or analyzed during this study are included in this article.

\section{Conflicts of Interest}

The authors declare that there are no conflicts of interest regarding the publication of this article.

\section{Acknowledgments}

The authors acknowledge the financial support provided by the National Natural Science Foundation of China (nos. 51874005 and 51878005) and the Science Research Foundation for Young and Middle-Aged Academic Backbones in Anhui University of Science and Technology.

\section{References}

[1] E. Dorn and O. Kaledin, "Modern and innovative shaft sinking and construction technology with examples from current projects/Moderne und innovative Schachtbautechnik am Beispiel aktueller Abteufprojekte," Geomechanics and Tunnelling, vol. 6, no. 5, pp. 574-581, 2013.

[2] A. H. Farazi, C. Quamruzzaman, N. Ferdous, M. A. Mumin, F. Mustahid, and A. F. Kabir, "Selection of shaft sinking method for underground mining in Khalashpir coal field, Khalashpir, Rangpur, Bangladesh," IOSR Journal of $\mathrm{Me}$ chanical and Civil Engineering, vol. 3, no. 5, pp. 15-20, 2012.

[3] T. Hara, A. Yashima, K. Sawada, K. Kariya, H. Tsuji, and N. Soga, "Small-diameter vertical shafts constructed in the shallow space of steep mountainous areas," Underground Space, vol. 4, no. 3, pp. 235-250, 2019.

[4] L. Zindi, "No. 17 Shaft project-overcoming 'fourth generation' technical challenges," in Proceedings of the Third International Platinum Conference:'Platinum in Transformation, Sun City, South Africa, October 2008.

[5] V. Didari and H. Gerçek, "Sinking of the deepest shaft in Turkey," Mining Science and Technology, vol. 7, no. 2, pp. 217-224, 1988.

[6] Z. Liu and Y. Meng, "Key technologies of drilling process with raise boring method," Journal of Rock Mechanics and Geotechnical Engineering, vol. 7, no. 4, pp. 385-394, 2015.

[7] F. Abdrabbo and K. Gaaver, "Challenges and uncertainties relating to open caissons," DFI Journal-The Journal of the Deep Foundations Institute, vol. 6, no. 1, pp. 21-32, 2012.

[8] Ł. Bołoz, "The analysis of shaft sinking progress as a function of technical and organizational parameters," Multidisciplinary Aspects of Production Engineering, vol. 2, no. 1, pp. 203-212, 2019.

[9] B. Q. Hong, "Discussion vertical structural stability of a drilled shaft in mud further," Journal of China Coal Society, vol. 33, pp. 121-125, 2008.

[10] X. C. Niu, B. Q. Hong, and R. S. Yang, “Theory study on axial structural stability of bored shafts filled with water," Journal of China Coal Society, vol. 4, pp. 463-466, 2005. 
[11] X. C. Niu, B. Q. Hong, and R. S. Yang, "Study on vertical structural stability of bored shafts filled part of water," Rock and Soil Mechanics, vol. 11, pp. 1897-1901, 2006.

[12] H. Cheng, J. M. Liu, and C. X. Rong, "Variable cross section shaft drilling lining's vertical stability in thick alluvium," Journal of China Coal Society, vol. 12, pp. 1351-1357, 2008.

[13] C. X. Rong, Y. Wang, J. M. Liu, and H. Cheng, "Numerical simulation on vertical stability critical height of variable cross section drilling shaft in deep alluvium," Journal of China Coal Society, vol. 32, pp. 1277-1281, 2007.

[14] W. J. Jiang, "Study on vertical structural stability of superdeep bored shaft submerged in slurry," Master's Dissertation, Tongji University, Shanghai, China, 2008.

[15] X. Li, Q. H. Zhang, J. Wanjun, and S. J. Sheng, Study on vertical structural stability of a super-deep drilled shaft in slurry," Chinese Journal of Underground Space and Engineering, vol. 5, pp. 1325-1330, 2009.

[16] L. Bo, L. Dongyang, and L. Jianjun, "The effect of earth pressure on ground settlement after frozen soil thawing in connect aisle construction of metro engineering," Journal of China Coal Society, vol. 33, pp. 1152-1156, 2008.

[17] Y. C. Wang and C. G. Deng, "Global stability analysis of bored shafts with initial bending imperfection and varying stiffness," Journal of Southeast University (Natural Science Edition), vol. 39, pp. 68-72, 2009.

[18] Ö. Civalek, "Free vibration of carbon nanotubes reinforced (CNTR) and functionally graded shells and plates based on FSDT via discrete singular convolution method," Composites Part B: Engineering, vol. 111, pp. 45-59, 2017.

[19] M. Arefi, S. Firouzeh, E. Mohammad-Rezaei Bidgoli, and Ö. Civalek, "Analysis of porous micro-plates reinforced with FG-GNPs based on reddy plate theory," Composite Structures, vol. 247, Article ID 112391, 2020.

[20] F. Ebrahimi, M. R. Barati, and Ö. Civalek, "Application of Chebyshev-Ritz method for static stability and vibration analysis of nonlocal microstructure-dependent nanostructures," Engineering with Computers, pp. 1-12, 2019.

[21] Ö. Civalek, B. Uzun, M. Ö. Yayll, and B. Akgöz, "Size-dependent transverse and longitudinal vibrations of embedded carbon and silica carbide nanotubes by nonlocal finite element method," The European Physical Journal Plus, vol. 135, no. 4, p. 381, 2020.

[22] M. H. Jalaei and Ö. Civalek, "On dynamic instability of magnetically embedded viscoelastic porous FG nanobeam," International Journal of Engineering Science, vol. 143, pp. 14-32, 2019.

[23] Ç. Demir and Ö. Civalek, "Torsional and longitudinal frequency and wave response of microtubules based on the nonlocal continuum and nonlocal discrete models," Applied Mathematical Modelling, vol. 37, no. 22, pp. 9355-9367, 2013.

[24] M. Gürses, B. Akgöz, and Ö. Civalek, "Mathematical modeling of vibration problem of nano-sized annular sector plates using the nonlocal continuum theory via eight-node discrete singular convolution transformation," Applied Mathematics and Computation, vol. 219, no. 6, pp. 3226-3240, 2012.

[25] A. Mohammed and C. Vipulanandan, "Testing and modeling the short-term behavior of lime and fly ash treated sulfate contaminated CL soil," Geotechnical and Geological Engineering, vol. 33, no. 4, pp. 1099-1114, 2015.

[26] M. Lei, D. Lin, C. Shi, J. Ma, and W. Yang, "A structural calculation model of shield tunnel segment: heterogeneous equivalent beam model," Advances in Civil Engineering, vol. 2018, Article ID 9637838, 16 pages, 2018.
[27] B. Yuan, L. Xiong, L. Zhai et al., "Transparent synthetic soil and its application in modeling of soil-structure interaction using optical system," Frontiers in Earth Science, vol. 7, p. 276, 2019.

[28] A. M. Raheem, C. Vipulanandan, and M. S. Joshaghani, "Nondestructive experimental testing and modeling of electrical impedance behavior of untreated and treated ultra-soft clayey soils," Journal of Rock Mechanics and Geotechnical Engineering, vol. 9, no. 3, pp. 543-550, 2017.

[29] H. Wan, Q. Wang, and Z. Zhang, “Anisotropic elastoplastic damage mechanics method to predict fatigue life of the structure," Advances in Materials Science and Engineering, vol. 2016, Article ID 7128347, 12 pages, 2016.

[30] K. Peng, Z. Liu, Q. Zou, Q. Wu, and J. Zhou, "Mechanical property of granite from different buried depths under uniaxial compression and dynamic impact: an energy-based investigation," Powder Technology, vol. 362, pp. 729-744, 2020.

[31] H. Lin, X. Zhang, Y. Wang et al., "Improved nonlinear nishihara shear creep model with variable parameters for rock-like materials," Advances in Civil Engineering, vol. 2020, Article ID 7302141, 15 pages, 2020.

[32] K. Peng, J. Zhou, Q. Zou, Y. Zhang, and G. Tan, “Deformation characteristics and failure modes of sandstones under discontinuous multi-level cyclic loads," Powder Technology, vol. 373, pp. 599-613, 2020.

[33] X. Shang and H. Tkalčić, "Point-source inversion of small and moderate earthquakes from $\mathrm{P}$-wave polarities and $\mathrm{P} / \mathrm{S}$ amplitude ratios within a hierarchical bayesian framework: implications for the geysers earthquakes," Journal of Geophysical Research: Solid Earth, vol. 125, no. 2, Article ID e2019JB018492, 2020.

[34] S. V. Sobolev, A. V. Sobolev, D. V. Kuzmin et al., "Linking mantle plumes, large igneous provinces and environmental catastrophes," Nature, vol. 477, no. 7364, pp. 312-316, 2011.

[35] Z. C. Fasoulakis, T. P. Avraam, and I. G. Raftoyiannis, "Dynamic buckling of partially-sway frames with varying stiffness using catastrophe theory," International Journal of Non-linear Mechanics, vol. 71, pp. 116-126, 2015.

[36] Y. Zuo, H. Wang, M. Yu, X. Dou, Z. Wu, and J. Wang, "Study on catastrophe theory of activation-induced prominence of faults under dynamic disturbance," Advances in Civil Engineering, vol. 2018, Article ID 2801957, 8 pages, 2018.

[37] B. Christaras, M. Argyriadis, and E. Moraiti, "Landslides in the marly slope of the kapsali area in kithira island, Greece," Bulletin of Engineering Geology and the Environment, vol. 73, no. 3, pp. 839-844, 2014.

[38] Z. Jixun, S. Jiaqing, Z. Haibo, R. Xuhua, and Q. Jiang, "Study on rock mass stability criterion based on catastrophe theory," Mathematical Problems in Engineering, vol. 2015, Article ID 850604, 7 pages, 2015.

[39] Y.-H. Chen, L. Chen, X.-Q. Wang, and G. Chen, "Critical buckling load calculation of piles based on cusp catastrophe theory," Marine Georesources \& Geotechnology, vol. 33, no. 3, pp. 222-228, 2015.

[40] Y. Zhou, X. Xu, X. Li, M. Li, and Y. Yang, "Study on catastrophe instability of support system in gypsum goaf based on energy dissipation theory," Advances in Civil Engineering, vol. 2018, Article ID 4293584, 9 pages, 2018.

[41] X. Kai-zong, X.-M. Liu, C.-X. Chen, Y.-F. Song, Z. Ou, and Y. Long, "Analysis of mechanism of bedding rock slope instability with catastrophe theory," Rock and Soil Mechanics, vol. 36, no. 2, pp. 477-486, 2015. 
[42] S. W. Ma, Z. Q. Luo, J. H. Hu et al., "Determination of intervening pillar thickness based on the cusp catastrophe model," Advances in Civil Engineering, vol. 2019, Article ID 8253589, 11 pages, 2019.

[43] J. Liu, "The height of water's influence on compound shaft drilling lining's vertical stability," China Mining Magzine, vol. 21, pp. 409-411, 2012.

[44] C. Couto and P. Vila Real, "Numerical investigation on the influence of imperfections in the local buckling of thin-walled I-shaped sections," Thin-Walled Structures, vol. 135, pp. 89108, 2019.

[45] A. Szychowski and K. Brzezińska, "Local buckling and resistance of continuous steel beams with thin-walled I-shaped cross-sections," Applied Sciences, vol. 10, no. 13, 2020.

[46] A. Fieber, L. Gardner, and L. Macorini, "Formulae for determining elastic local buckling half-wavelengths of structural steel cross-sections," Journal of Constructional Steel Research, vol. 159, pp. 493-506, 2019.

[47] X. Kai-zong, C. X. Chen, Z. D. Lu, Y. F. Song, and Y. C. Zhou, "Analysis of sensitivity factors for stability of soft and hard rock interbedded slope," Journal of Wuhan University of Technology (Transportation Science and Engineering Edition), vol. 4, pp. 729-732, 2013.

[48] A. A. Shahri, M. Saneie, S. A. Hosseini, and R. Asheghi, "Updating the neural network sediment load models using different sensitivity analysis methods: a regional application," Journal of Hydroinformatics, vol. 22, no. 3, pp. 562-577, 2020.

[49] F. Golzar, D. Nilsson, and V. Martin, "Forecasting wastewater temperature based on artificial neural network (ANN) technique and monte carlo sensitivity analysis," Sustainability, vol. 12, no. 16, 2020.

[50] M. Stergiadi, N. Di Marco, D. Avesani, M. Righetti, and M. Borga, "Impact of geology on seasonal hydrological predictability in alpine regions by a sensitivity analysis framework," Water, vol. 12, no. 8, 2020. 